\title{
Cancer history, insurance coverage, and cost-related medication nonadherence in Medicare beneficiaries, 2013-2018
}

\author{
Meng Li, ScM, PhD, and Mark Bounthavong, PharmD, PhD
}

\section{What is already known about this subject}

- Nonelderly cancer survivors are at a greater risk of cost-related medication nonadherence compared with those without a history of cancer.

- No health insurance, enrollment in a high-deductible plan, and no prescription drug coverage are associated with a higher likelihood of cost-related medication nonadherence.
What this study adds

- Among Medicare beneficiaries, cancer survivors were more likely to report cost-related medication nonadherence than those without a history of cancer.

- Having unsubsidized Medicare Part D was associated with higher likelihood of reporting cost-related medication nonadherence, whereas subsidized Part D was not associated with such nonadherence.

- Medicare Advantage was associated with lower likelihood of cost-related medication nonadherence compared with traditional fee-for-service Medicare.

\section{Author affiliations \\ Meng Li, ScM, PhD, Department of Health Service Research, University of Texas MD Anderson Cancer Center, Houston. Mark Bounthavong, PharmD, PhD, University of California San Diego Skaggs School of Pharmacy \& Pharmaceutical Sciences, La Jolla.}

\section{AUTHOR CORRESPONDENCE: \\ Meng Li, 832.728.8359; \\ Mli14@mdanderson.org}

J Manag Care Spec Pharm 2021;27(12):1750-56

Copyright $\odot 2021$, Academy of Managed Care Pharmacy. All rights reserved.

\section{ABSTRACT}

BACKGROUND: Cancer survivors are at risk of financial hardships and cost-related medication nonadherence, particularly among those without adequate insurance coverage.

OBJECTIVE: To examine the association between cancer history and cost-related medication nonadherence, as well as the association between insurance coverage and nonadherence among Medicare beneficiaries.

METHODS: We used the 2013-2018 Medicare Current Beneficiary Survey Public Use File, a survey on the health, health service utilization, access to care, and satisfaction among a nationally representative sample of Medicare beneficiaries. Cost-related medication nonadherence was defined as often or sometimes reporting any of the following: (1) took smaller dose of medication, (2) skipped doses to make medication last, (3) delayed medication because of cost, and (4) not get medication because of cost. Logistic regression was used to estimate the odds ratio of cost-related nonadherence associated with cancer history, adjusting for survey year and sociodemographic characteristics of the respondents, including age, sex, race and ethnicity, highest grade completed, income level, marital status, and number of chronic conditions. We also included Medicare Part $D$, an interaction between Part $D$ and the low-income subsidy, and Medicare Advantage in the model to examine the effect of insurance coverage on cost-related nonadherence.

RESULTS: From 2013 to 2018, there were 12,492 cancer survivors and 53,262 respondents without a history of cancer in our sample, and $16.5 \%$ reported cost-related medication nonadherence. After adjusting for characteristics of the respondents, cancer survivors were more likely than those without a history of cancer to report cost-related medication nonadherence (adjusted OR=1.10; 95\% $\mathrm{Cl}=1.02-1.19)$. Having unsubsidized Part $\mathrm{D}-$ Part D without the low-income subsidy-was associated with a greater likelihood of reporting cost-related medication nonadherence (adjusted $\mathrm{OR}=1.63,95 \% \mathrm{Cl}=1.49-1.78$ ), while having subsidized Part $D$ was not (adjusted $\mathrm{OR}=0.96 ; 95 \% \mathrm{Cl}=0.85-1.08$ ). Finally, being on Medicare Advantage was associated with lower likelihood of reporting cost-related nonadherence compared with traditional feefor-service Medicare (adjusted OR=0.86; 95\% $\mathrm{Cl}=0.80-0.92)$.

CONCLUSIONS: Expanding the low-income subsidy and capping out-of-pocket drug expenditure can be effective policy options to reduce cost-sharing burden and costrelated nonadherence. 
Prescription drug spending has risen rapidly in recent years in the United States. Inflation-adjusted per capita spending on retail prescription drugs increased from $\$ 582$ in 2000 to $\$ 1,025$ in 2017. ${ }^{1}$ For Medicare beneficiaries, the share of total prescription drug spending paid out-of-pocket increased from $2 \%$ in 2000 to $30 \%$ in 2017, with a sharp increase from $2 \%$ to $18 \%$ around the time when Part D went into effect. Increased cost sharing has been shown to be associated with lower rates of drug initiation, worse adherence, and more frequent discontinuation of therapy. ${ }^{2}$ Such nonadherence results in worse health outcomes and may lead to higher overall health care spending. ${ }^{3}$

Cancer survivors are at a greater risk of incurring high out-of-pocket expenditures and financial hardships compared with those without a history of cancer. ${ }^{4-7} \mathrm{~A}$ recent study found that the average annual out-of-pocket spending per person was $\$ 1,000$ among cancer survivors and $\$ 622$ among persons without a cancer history. ${ }^{5}$ Approximately $25 \%$ of cancer survivors reported material hardship, such as having problems paying medical bills, and $34 \%$ reported psychological hardship, such as worrying about medical bills. ${ }^{5}$ Studies have found that high financial burden adversely affected medication adherence in some cancer patients and subsequently increased mortality. ${ }^{8-10}$

The high prevalence of financial hardships and the resulting cost-related medication nonadherence among cancer survivors suggest that insurance coverage may not be adequate in this population, given the rapidly increasing prices of cancer medicines. ${ }^{11}$ Previous research on nonelderly cancer survivors found that no health insurance, enrollment in a high-deductible plan, and no prescription drug coverage were associated with a higher likelihood of cost-related medication nonadherence. ${ }^{12}$

For elderly cancer survivors, there is a lack of evidence on how Medicare Part D prescription drug coverage, the low-income subsidy, and Medicare Advantage influenced cost-related medication nonadherence. Medicare Advantage plans have a cap on annual out-of-pocket medical spending (eg, cancer drugs administered at a doctor's office), which protects patients from unlimited financial liability. Part D prescription drug coverage (eg, oral cancer drugs) does not have an out-of-pocket spending cap, but some patients qualify for the low-income subsidy, which significantly reduces their out-of-pocket spending on prescription drugs. A study from 2007 found that Medicare beneficiaries without the low-income subsidy had higher adjusted odds of reporting cost-related medication nonadherence compared with those with the subsidy. ${ }^{13}$

In this study, we delineated how cancer history and health insurance (Medicare Advantage and Part D with and without the low-income subsidy) influenced cost-related medication nonadherence, as well as characterized the recent trends in such nonadherence among Medicare beneficiaries.

\section{Methods}

We used data from the Medicare Current Beneficiary Survey Public Use File (MCBS PUF) from 2013 to 2018 to identify adults with and without a cancer history. The MCBS PUF is a publicly available, in-person survey of a representative national sample of the Medicare population on health, health care use, access to care, and satisfaction with care, with a serial cross-sectional design. MCBS PUF data are available annually from 2013 to 2018, except for the year 2014. All questions in the PUF are self-reported. The survey sample design includes stratification, clustering, multiple stages of selection, and disproportionate sampling. The survey weights reflect this complex design, as well as adjustments for nonresponse.

For our study, cancer survivors were defined as those who reported ever being diagnosed with nonskin cancer. The MCBS PUF does not distinguish between melanoma and nonmelanoma skin cancer. Therefore, we excluded all skin cancer in this analysis. Sociodemographic characteristics included age, sex, race and ethnicity, highest grade completed, income level, marital status, number of chronic conditions, Medicare Advantage, Medicare Part D, and the low-income subsidy. The outcome of interest was costrelated medication nonadherence. The MCBS PUF includes a series of 4 questions on cost-related medication nonadherence. The respondents were asked if they have often, sometimes, or never: (1) taken smaller doses than prescribed of a medicine to make the medicine last longer; (2) skipped doses to make the medicine last longer; (3) delayed getting a prescription filled because the medicine cost too much; and (4) decided not to fill a prescription because it cost too much. If the beneficiary responded "often" or "sometimes" to any of the 4 questions, we considered them as having cost-related medication nonadherence.

We first examined the sociodemographic characteristics of cancer survivors and those without a history of cancer using frequencies and survey-weighted proportions with Stata's svy commands, the latter reflecting the distributions of characteristics in the entire Medicare population, accounting for the complex survey design of MCBS. We then estimated the trends over time in survey-weighted proportions of respondents reporting cost-related nonadherence among cancer survivors and those without a history of cancer. Finally, we used multivariable logistic regression with survey weights to estimate the odds ratio (OR) of cost-related medication nonadherence associated 
with cancer history, adjusting for the respondent's age, sex, race and ethnicity, highest grade completed, income level, marital status, number of chronic conditions, and survey year. We further included Medicare Advantage, the main effect of Part D, and an interaction between Part D and the low-income subsidy to examine how these types of insurance coverage were associated with nonadherence.

All analyses were conducted in Stata 15 (StataCorp). Statistical tests were 2-sided and significance level was set at 0.05 .

\section{Results}

There were 12,492 cancer survivors and 53,262 respondents without a history of cancer in our sample from 2013 to 2018. Compared to those without a history of cancer, cancer survivors were older $(P<0.001)$, more likely to be female $(P<0.001)$, non-Hispanic White $(P<0.001)$, had higher education $(P<0.001)$ and income $(P<0.001)$, were more likely to be married or widowed $(P<0.001)$, less likely to have the low-income subsidy $(\mathrm{P}<0.001)$, slightly more likely to have Medicare Advantage $(P=0.049)$, and had a higher number of chronic conditions $(\mathrm{P}<0.001$; Table 1$)$.

Between 2013 and 2018, approximately 16.5\% of our study sample reported cost-related medication nonadherence. The proportion of respondents who reported cost-related nonadherence was slightly, although not statistically, significantly higher among cancer survivors than those without a cancer history (Table 1 and Supplementary Figure 1, available in online article). Among cancer survivors, the proportion of patients who reported cost-related nonadherence first increased from $16.4 \%$ in 2013 to $18.0 \%$ in 2016 and then decreased to 15.1\% in 2018. For those without a history of cancer, the proportion that reported costrelated nonadherence first increased from 16.1\% in 2013 to $17.5 \%$ in 2016 and then decreased to $14.5 \%$ in 2018.

Among cancer survivors, the greatest decline in nonadherence was seen in the population with the low-income subsidy, and the gap between those with and without the subsidy was closing: from 2013 to 2018, the proportion of cancer survivors with the low-income subsidy who reported cost-related medication nonadherence decreased from $28.3 \%$ to $18.4 \%$, whereas the proportion of cancer survivors without the subsidy who reported cost-related nonadherence remained largely unchanged, around 15.2\% (Supplementary Figure 2, panel A, available in online article).

Among those without a cancer history, we similarly observed a closing gap between those with and without the subsidy (Supplementary Figure 2, panel B): from 2013 to 2018, the proportion of noncancer survivors with the low-income subsidy who reported cost-related medication nonadherence decreased from $21.0 \%$ to $17.2 \%$, whereas among those without the subsidy the proportion remained around $13.6 \%$.

After adjusting for the respondent's sociodemographic characteristics and survey year, cancer survivors were more likely to report cost-related medication nonadherence (adjusted $\mathrm{OR}=1.10,95 \% \mathrm{CI}=1.02-1.19)$ compared with those without a history of cancer (Figure 1). Sociodemographic characteristics that were associated with a significantly higher likelihood of nonadherence across cancer survivors and those without a cancer history included younger age, female, more chronic conditions, non-Hispanic Black and other race, lower education, lower income, and being divorced or separated.

Having unsubsidized Part D (Part D without the lowincome subsidy) was associated with a greater likelihood of reporting cost-related medication nonadherence (adjusted $\mathrm{OR}=1.63$, 95\% CI=1.49-1.78). However, having subsidized Part D (Part D with the low-income subsidy) was not associated with reporting cost-related nonadherence (adjusted $\mathrm{OR}=0.96 ; 95 \% \mathrm{CI}=0.85-1.08$ ). Finally, being on Medicare Advantage was associated with lower likelihood of reporting cost-related nonadherence (adjusted $\mathrm{OR}=0.86 ; 95 \%$ $\mathrm{CI}=0.81-0.92)$.

\section{Discussion}

Using a nationally representative sample of Medicare beneficiaries, we found that cancer survivors were more likely to report cost-related medication nonadherence than those without a history of cancer. Younger age, female, more chronic conditions, non-Hispanic Black and other race, lower education, lower income, and being divorced or separated were also found to be associated with higher cost-related medication nonadherence. These findings corroborated existing knowledge on cost-related medication nonadherence and patient characteristics associated with such nonadherence among cancer survivors. ${ }^{12,14-19}$

Moreover, we found that the proportion of patients who reported cost-related medication nonadherence declined in recent years for cancer survivors and those without a history of cancer, particularly among those with the lowincome subsidy. This decline could be due to the gradual closing of the Medicare Part D donut hole.

The most interesting and important finding of this study is that having unsubsidized Medicare Part D was associated with higher likelihood of reporting cost-related medication nonadherence, whereas having subsidized Part D was not. This finding highlighted the protective effect of the 


\section{TABLE 1 Sociodemographic Characteristics of Cancer Survivors and Those Without a History of Cancer}

\begin{tabular}{|c|c|c|c|c|c|}
\hline & \multicolumn{2}{|c|}{ Cancer survivors $(\mathrm{n}=12,492)$} & \multicolumn{2}{|c|}{ Without cancer history $(n=53,262)$} & \multirow[b]{2}{*}{$P$ value } \\
\hline & $\mathbf{n}$ & weighted \% & $\mathbf{n}$ & weighted \% & \\
\hline \multicolumn{6}{|l|}{ Age, years } \\
\hline$<65$ & 1,252 & 11.2 & 10,092 & 16.6 & \multirow{3}{*}{$<0.001$} \\
\hline $65-75$ & 3,750 & 44.7 & 18,062 & 50.7 & \\
\hline$\geq 75$ & 7,490 & 44.1 & 25,108 & 32.8 & \\
\hline \multicolumn{6}{|l|}{ Sex } \\
\hline Male & 5,572 & 44.0 & 24,570 & 46.2 & \multirow{2}{*}{$<0.001$} \\
\hline Female & 6,920 & 56.0 & 28,692 & 53.8 & \\
\hline \multicolumn{6}{|l|}{ Race and ethnicity } \\
\hline Non-Hispanic White & 9,991 & 79.5 & 38,656 & 73.3 & \multirow{4}{*}{$<0.001$} \\
\hline Non-Hispanic Black & 940 & 7.6 & 5,756 & 10.1 & \\
\hline Hispanic & 907 & 6.9 & 5,456 & 9.2 & \\
\hline Other & 654 & 6.0 & 3,394 & 7.3 & \\
\hline \multicolumn{6}{|l|}{ Highest grade completed } \\
\hline Less than high school & 2,090 & 14.4 & 10,597 & 17.0 & \multirow{3}{*}{$<0.001$} \\
\hline High school or equivalent & 4,377 & 34.1 & 19,150 & 34.0 & \\
\hline More than high school & 5,979 & 51.6 & 23,253 & 49.0 & \\
\hline \multicolumn{6}{|l|}{ Income group } \\
\hline$<\$ 25,000$ & 4,753 & 35.1 & 23,834 & 39.4 & \multirow[t]{2}{*}{$<0.001$} \\
\hline$\geq \$ 25,000$ & 7,636 & 64.9 & 28,966 & 60.7 & \\
\hline \multicolumn{6}{|l|}{ Marital status } \\
\hline Married & 6,459 & 54.9 & 25,062 & 53.0 & \multirow{4}{*}{$<0.001$} \\
\hline Widowed & 3,427 & 22.7 & 13,251 & 20.1 & \\
\hline Divorced/separated & 1,859 & 16.9 & 8,309 & 17.6 & \\
\hline Never married & 736 & 5.6 & 6,600 & 9.4 & \\
\hline \multicolumn{6}{|l|}{ Part D } \\
\hline Yes & 9,433 & 73.9 & 40,967 & 73.7 & \multirow{2}{*}{0.639} \\
\hline No & 3,059 & 26.1 & 12,295 & 26.3 & \\
\hline \multicolumn{6}{|l|}{ Low-income subsidy } \\
\hline Yes & 2,264 & 17.0 & 14,101 & 22.0 & \multirow{2}{*}{$<0.001$} \\
\hline No & 10,228 & 83.0 & 39,161 & 78.0 & \\
\hline \multicolumn{6}{|l|}{ Medicare Advantage } \\
\hline Yes & 4,318 & 35.3 & 19,205 & 34.2 & \multirow{2}{*}{0.049} \\
\hline No & 8,174 & 64.7 & 34,057 & 65.9 & \\
\hline \multicolumn{6}{|l|}{ Number of chronic conditions } \\
\hline 0 & 1,224 & 11.6 & 6,997 & 14.7 & $<0.001$ \\
\hline $1-2$ & 6,452 & 52.2 & 28,693 & 54.2 & \\
\hline$\geq 3$ & 4,813 & 36.3 & 17,572 & 31.2 & \\
\hline Reported cost-related medication nonadherence & 1,661 & 16.8 & 6,895 & 16.6 & 0.166 \\
\hline
\end{tabular}




\section{FIGURE 1 Association of Cancer History, Insurance Coverage, and Other Sociodemographic Characteristics of Medicare Beneficiaries with Cost-Related Medication Nonadherence}

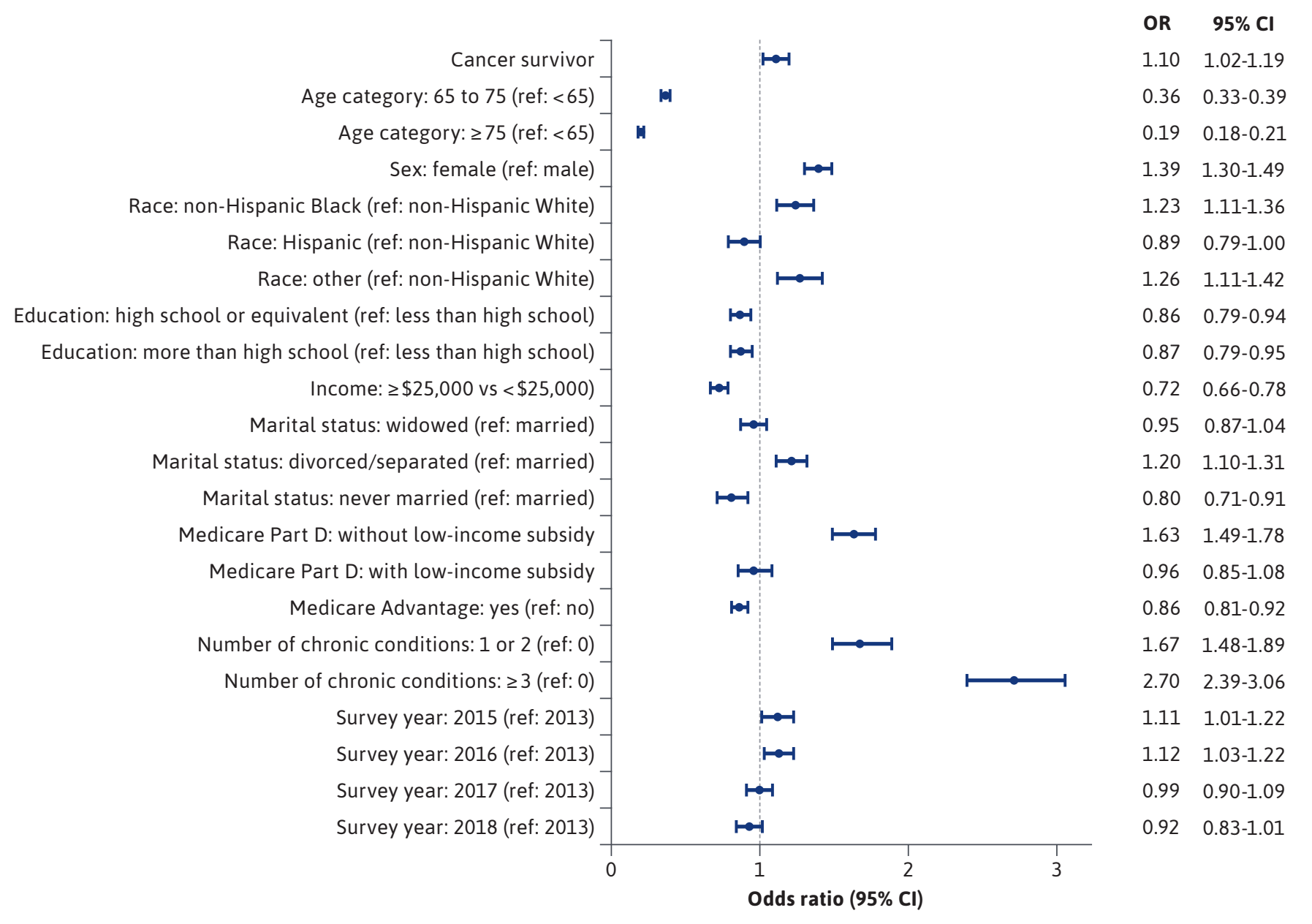

Note: The coefficient for the interaction term between Part D and the low-income subsidy was 0.59 (0.53-0.65). The coefficient for Medicare Part D with the

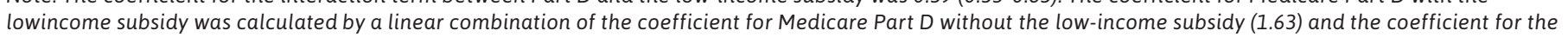
interaction term between Part $D$ and the low-income subsidy (0.59).

OR=odds ratio; Ref $=$ reference.

low-income subsidy on the out-of-pocket burden among Part D enrollees and the need to expand the subsidy to a broader population.

The 2021 resource limits for the low-income subsidy are $\$ 7,970$ for singles and $\$ 11,960$ for married couples for the full subsidy and $\$ 13,290$ (\$26,520 if married) for the partial subsidy. ${ }^{2,20}$ Under this resource limit, many of those who live in near poverty are not eligible for the subsidy. The outof-pocket expenditure faced by those who do not qualify for the subsidy can be quite significant, especially among those who are on high-cost specialty drugs. Previous research found that in 2012 the mean annual out-of-pocket Part D spending among Medicare beneficiaries taking at least 1 specialty drug who did not qualify for the low-income subsidy was $\$ 3,557 .^{21}$

We further found that those on Medicare Advantage reported lower likelihood of cost-related medication nonadherence, compared with those with fee-for-service Medicare. This may be because, unlike fee-for-service Medicare, Medicare Advantage plans have an out-of-pocket maximum. Although Part D spending does not count towards the out-of-pocket maximum, capping nonretail 
pharmacy out-of-pocket spending can still lower the overall financial risk for patients, which may explain the lower risk of nonadherence in the Medicare Advantage population.

These findings underscored the importance of adequate insurance coverage for reducing cost-related medication nonadherence. Without adequate coverage, merely having health insurance does not necessarily ensure medication affordability, due in part to the rising costs of prescription drugs. For example, the average annual cost of anticancer medicines increased from less than $\$ 50,000$ for drugs launched in 2000 to near $\$ 150,000$ for drugs launched in 2018. ${ }^{11}$ Capping beneficiaries' out-of-pocket liability for prescription drugs and raising the resource limit for the low-income subsidy program can be effective policy options to reduce cost-sharing burden from prescription drugs and cost-related medication nonadherence.

\section{LIMITATIONS}

There are several limitations in this analysis. First, cancer history was self-reported, and there was no information on whether the respondent still had cancer. Cost-sharing burden and cost-related medication nonadherence may differ significantly between those who have active disease and those whose cancer is in remission. In our analysis, we were unable to distinguish between these 2 subgroups.

Next, medication nonadherence was also self-reported, and direct measures of adherence, such as drug administration, were not available. Additionally, nonadherence to nonpharmacologic treatments was unavailable in MCBS PUF. Moreover, other forms of financial assistance with paying for prescription drugs, such as coupon cards and other patient-assistance programs, were not observed in our data. One previous study found that specialty drug coupons lowered out-of-pocket costs and may have improved adherence. ${ }^{9}$ These tools are becoming more common and may have contributed to the decline in cost-related medication nonadherence in recent years.

Finally, information on out-ofpocket spending and financial difficulty is not available in the MCBS PUF, and these factors may mediate the effect of cancer history on costrelated nonadherence.

\section{Conclusions}

Findings from this study highlighted the consequences of the financial burden from paying for prescription drugs among cancer survivors and the need for improving insurance coverage and expanding subsidies to alleviate burden and improve adherence.

\section{DISCLOSURES}

For this study, Li was partially supported by a research grant from the National Cancer Institute (R01CA225647). The sponsor had no role in the design or implementation of the study, analysis or interpretation of the data, or drafting or approval the manuscript. The authors report no conflicts of interest.

\section{REFERENCES}

1. Kamal R, Cox C, McDermott D. What are the recent and forecasted trends in prescription drug spending? Health System Tracker. February 20, 2019. Accessed October 5, 2021. https://www.healthsystemtracker.org/chart-collection/ recent-forecasted-trends-prescriptiondrug-spending/\#item-start

2. Goldman DP, Joyce GF, Zheng Y. Prescription drug cost sharing: associations with medication and medical utilization and spending and health. JAMA. 2007;298(1):61-69. doi:10.1001/ jama.298.1.61
3. Cutler RL, Fernandez-Llimos F, Frommer M, Benrimoj C, GarciaCardenas V. Economic impact of medication non-adherence by disease groups: a systematic review. BMJ Open. 2018;8(1):e016982. doi:10.1136/ bmjopen-2017-016982

4. Gordon LG, Merollini KMD, Lowe A, Chan RJ. A systematic review of financial toxicity among cancer survivors: we can't pay the co-pay. Patient. 2017;10(3):295309. doi:10.1007/s40271-016-0204-x

5. Ekwueme DU, Zhao J, Rim SH, et al. Annual out-of-pocket expenditures and financial hardship among cancer survivors aged 18-64 years - United States, 2011-2016. MMWR Morb Mortal Wkly Rep. 2019;68(22):494-99. doi:10.15585/mmwr. $\mathrm{mm} 6822 \mathrm{a} 2$

6. Pisu M, Azuero A, McNees P, Burkhardt J, Benz R, Meneses K. The out of pocket cost of breast cancer survivors: a review. J Cancer Surviv. 2010;4(3):20209. doi:10.1007/s11764-010-0125-y

7. Odahowski CL, Zahnd WE, Zgodic A, et al. Financial hardship among rural cancer survivors: an analysis of the Medical Expenditure Panel Survey. Prev Med (Baltim). 2019;129S:105881. doi:10.1016/j. ypmed.2019.105881

8. Neugut AI, Subar M, Wilde ET, et al. Association between prescription copayment amount and compliance with adjuvant hormonal therapy in women with early-stage breast cancer. J Clin Oncol. 2011;29(18):2534-42. doi:10.1200/ JCO.2010.33.3179

9. Streeter SB, Schwartzberg L, Husain N, Johnsrud M. Patient and plan characteristics affecting abandonment of oral oncolytic prescriptions. Am J Manag Care. 2011;17(Suppl 5):SP38-44.

10. Hershman DL, Shao T, Kushi LH, et al. Early discontinuation and non-adherence to adjuvant hormonal therapy are associated with increased mortality in women with breast cancer. Breast Cancer Res Treat. 2011;126(2):529-37. doi:10.1007/ s10549-010-1132-4 
11. IQVIA Institute. Global oncology trends 2019: therapeutics, clinical development, and health system implications. May 30, 2019. Accessed May 2, 2021. https://www. iqvia.com/insights/the-iqvia-institute/ reports/global-oncology-trends-2019

12. Zhao J, Zheng Z, Han X, et al. Cancer history, health insurance coverage, and cost-related medication nonadherence and medication cost-coping strategies in the United States. Value Health. 2019;22(7):762-67. doi:10.1016/j. jval.2019.01.015

13. Wei II, Lloyd JT, Shrank WH. The relationship between the low-income subsidy and cost-related nonadherence to drug therapies in Medicare Part D. J Am Geriatr Soc. 2013;61(8):1315-23. doi:10.1111/ jgs.12364

14. Kaul S, Avila JC, Mehta HB, Rodriguez AM, Kuo Y-F, Kirchhoff AC. Cost-related medication nonadherence among adolescent and young adult cancer survivors. Cancer. 2017;123(14):2726-34. doi:10.1002/cncr.30648
15. Nekhlyudov L, Madden J, Graves AJ, Zhang F, Soumerai SB, Ross-Degnan D. Cost-related medication nonadherence and cost-saving strategies used by elderly Medicare cancer survivors. J Cancer Surviv. 2011;5(4):395-404. doi:10.1007/ s11764-011-0188-4

16. Lee M, Khan MM. Gender differences in cost-related medication non-adherence among cancer survivors. J Cancer Surviv. 2016;10(2):384-93. doi:10.1007/ s11764-015-0484-5

17. Gu D, Shen C. Cost-related medication nonadherence and cost-reduction strategies among elderly cancer survivors with self-reported symptoms of depression. Popul Health Manag. 2020;23(2):132-39. doi:10.1089/pop.2019.0035

18. Zhang JX, Meltzer DO. Risk factors for cost-related medication non-adherence among older patients with cancer. Integr Cancer Sci Ther. 2015;2(6):300-04.
19. Li M, Bounthavong M. Medicare beneficiaries, especially unsubsidized minorities, struggle to pay for prescription drugs: results from the Medicare Current Beneficiary Survey. J Gen Intern Med. 2020;35(4):1334-36. doi:10.1007/ s11606-019-05204-2

20. Centers for Medicare \& Medicaid Services. 2021 resource and cost-sharing limits for low-income subsidy (LIS). October 30, 2020. Accessed October 5, 2021. https://www.cms.gov/files/ document/2021-lis-resource-limitsmemo.pdf

21. Trish E, Xu J, Joyce G. Medicare beneficiaries face growing out-of-pocket burden for specialty drugs while in catastrophic coverage phase. Health Aff (Millwood). 2016;35(9):1564-71. doi:10.1377/ hlthaff.2016.0418 